\title{
Towards a Net Zero Building Cluster Energy Systems Analysis for US Army Installations
}

\author{
Dr. Alexander Zhivov ${ }^{1}$, Dr. Richard J. Liesen ${ }^{1}$, Dr. Stephan Richter ${ }^{2}$, Dr. Reinhard Jank ${ }^{3}$, Mr. David \\ M. Underwood ${ }^{1}$, Mr. Dieter Neth ${ }^{4}$, Mr. Alfred Woody ${ }^{5}$, Dr. Curt Björk ${ }^{6}$, Mr. Scot Duncan ${ }^{7}$ \\ ${ }^{1}$ U.S. Army Engineer Research \& Development Center; Champaign, IL, USA \\ ${ }^{2}$ GEF Ingenieur AG, Leimen, Germany \\ ${ }^{3}$ Volkswohnung GmbH, Karlsruhe, Germany \\ ${ }^{4}$ Senergy GmbH, Mossingen, Germany \\ ${ }^{5}$ Ventilation/Energy Applications, PLLC, Norton Shores, Michigan \\ ${ }^{6}$ Curt Björk Consulting, Naxos Island, Greece \\ ${ }^{7}$ Retrofit Originality Incorporated, Lake Forest, California \\ *Corresponding author.E-mail: Alexander.M.Zhivov@usace.Army.mil
}

\begin{abstract}
U.S. federal agencies are required by law to eliminate fossil fuel use in new and renovated facilities by 2030, and to reduce overall facility energy usage by 30\% by 2015 (EISA 2007). Army policy is to achieve 5 net zero energy installations by 2021, 25 net zero energy installations by 2031 and for all installations to achieve net zero energy status by 2058.

The Army operates what are essentially small campuses, or clusters of buildings on its installations. The US Department of Energy (DOE) is focused on the national grid scale or on individual buildings, while the commercial focus is on retrofits to individual buildings. There is a lack of tools and there are only few case studies worldwide that address dynamics of energy systems at the community scale. The Army's future building energy requirements is a mixture of ultra-low and high energy intensity facilities. Achieving net zero energy economically in these clusters of buildings will require a seamless blend of energy conservation in individual buildings and building systems automation, utility management, and control, power delivery systems with the capability to offer integration of onsite power generation (including renewable energy sources) and energy storage.

When buildings are handled individually each building is optimized for energy efficiency to the economic energy efficiency optimum and then renewables are added until the building is "net zero." This process works for buildings with a low energy intensity process for its mission, such as barracks and administrative buildings. When the mission of the building requires high energy intensity such as in a dining facility, data center, etc., this optimization process either will not end up with a net zero energy building, or large amounts of renewables will be added resulting in the overall technical solution that is not cost effective. However when buildings are clustered together, after each building is designed to its economic energy efficient option, the building cluster is also energy optimized taking advantages of the diversification between energy intensities, scheduling, and waste energy streams use. The optimized cluster will minimize the amount of renewables needed to make the building cluster net zero. This paper describes this process and demonstrates it using as an example a cluster of buildings at Fort Irwin, California.
\end{abstract}

Keywords: Energy efficiency, Energy generation and distribution, Building cluster, Renewable energy source, Integrated optimization process.

\section{Army Energy Policy Overview}

Buildings contribute to a large fraction of energy usage worldwide. In the United States alone, buildings consume about $40 \%$ of total energy, including $71 \%$ of electricity and $54 \%$ of natural gas. Army alone spends more than $\$ 1$ billion for building related energy expenses. The Army Energy Security Implementation Strategy sets the general direction for the Army including elimination of energy waste in existing facilities, increase in energy efficiency in new construction and renovations, and reduced dependence on fossil fuels. The 2005 Energy Policy Act requires that federal facilities be built to achieve at least a 30\% energy savings over the 2004 International Energy Code or ASHRAE Standard 90.1-2004 as appropriate, and that energy efficient designs must be life-cycle cost effective. According to the Energy Independence and Security Act (EISA 2007), new buildings and buildings undergoing major renovations shall be designed so that consumption of energy generated offsite or on-site using fossil fuels is reduced, as compared with such energy consumption by a similar building in fiscal year 2003 (as measured by Commercial 
Buildings Energy Consumption Survey (CBECS) or Residential Energy Consumption Survey (RECS) data from the Energy Information Agency), by 55\% in 2010, 80\% by 2020, and $100 \%$ by 2030.

In an increasingly energy constrained world, the Army and its logistic support envisions a future where its energy needs are designed and fulfilled by a suite of ultra low energy solution options that can be tailored for adaptation at any Army installation depending on climatic zone, mission needs, mix of building types, availability of different sources of renewable energy, etc. Presently there is no overarching power "delivery/energy storage/demand" architecture and methodology to accomplish this. Commanders also need the capability to meet their energy use reduction goals with the requirements for energy security, affordability, environmental footprint, occupant wellbeing and productivity, and building sustainability (as appropriate) depending on the threat conditions, mission needs, utility market prices, etc.

\section{Integrated Optimization Process}

The Army is rapidly changing its views on energy usage to reconsider energy conservation and efficiency [1]. Army installations are essentially small campuses, comprised of clusters of buildings. Energy efficiency requirements dictate a serious tracking of all waste energy flows, their use, and their storage within the "Installation Boundaries," with consideration of realistic thermodynamic constraints for all rejected energy. To accomplish these ends is neither straightforward nor inexpensive. The concept of improved standards and increased energy efficiency in buildings can help individual buildings achieve more efficiency. However, it is difficult to adapt existing buildings to achieve Net Zero Energy (NZE) goals on their own. Net Zero Energy cannot be met with efficiency increases alone; there must be efficiency gains on the conversion, supply, and distribution side as well. Achieving NZE cost effectively will be possible if an optimum mix of demand reduction, energy distribution, energy supply, and renewable sources are put in place at a community (installation) or building cluster scale.

The knowledge base needed to build, renovate, and maintain Army installations with the highest levels of energy efficiency do not penetrate far enough into the market. There are a multitude of available technologies [2] related to the building envelope, ventilation, advanced "low exergy" heating and cooling systems, central energy plants with co- and tri-generation, hybrid and high efficient lighting systems designs and technologies, integrated solar thermal and electrical systems, etc. Due to economies of scale, a number of technologies, like cogeneration or combined heat and power, waste heat recovery, biomass, geothermal energy, solar heating (and cooling), and others, are more efficient - in technical and economic terms - when used in large systems rather than in small or individual building systems. Taking advantage of these technologies will enable an optimized system to reduce the primary energy consumption achieved (including demand and supply) to the best available standards, and also to lower costs.

Community energy planning and central system optimization do not require development of a new approach. Energy planning methods in the past were used to design the components of the energy supply systems, e.g., a district heating network connected to local combined heating and power plant was often planned by the local utility using an "optimization strategy." Existing energy planning methods used energy balancing methods and available planning models that include environmental models. This approach was then, and is still today, unfamiliar to energy planners. An important feature that is necessary in community-wide energy planning is the integrated consideration of supply and demand, which leads to optimized solutions. Therefore, it is the objective to apply the principles of such a holistic approach to community energy planning and to provide the necessary methods and instruments to master planners, decision makers, and stakeholders.

Thermal Energy Systems consist of three major elements: generation of energy, distribution of energy, and the demand of energy. The goal is to find the optimum for the entire energy system, where each element requires consideration. This process can be outlined in a several step analysis: 


\subsection{Site Setup and Analysis}

Determine building locations, geography, utility locations, etc.:

1. Gather Building Energy Data for Benchmarking - gather utility bills, available energy demand data, etc., for all new and existing buildings.

2. Characterize All Buildings in Inventory - determine the building type and use characteristics and determine appropriate building model to simulate for demands.

3. Pre-Planning and Data Gathering - Gather all building and site data from stakeholders and partners. Gather all of the data with no pre-conceived answers.

\subsection{Building Simulation}

Simulate base and efficient cases for each building type selected in the site inventory:

1. Determine Baseline Model - simulate each building classification type identified in the building characterization step from the inventory.

2. Energy Efficiency Measures (EEM) - determine the appropriate building energy efficiency measures for each simulated building type.

3. Simulate the Energy Efficiency Cases - simulate the energy efficiency scenarios and produce the optimization curve for each building type.

4. Generate the EEM Project List - during the optimization process generate the project list to bring the building to net zero ready status.

5. Produce Building Energy Use Profiles with Peaks - Develop hourly, monthly, and annual use profiles for all demand energy

\subsection{Distribution and Supply Optimization}

Take data from the building efficient cases to setup the load and network design to determine the optimal distribution and supply network:

1. Integrate All Building Energy Demands - use the efficient case for the building cluster to be analyzed.

2. Develop Load Duration Curves - integrate all energy demands for the building cluster to be optimized and produce curves.

3. Use Hydraulic Simulation - develop the hydraulic parameters for integrated heating and/or cooling systems.

4. Determine Supply Equipment Inventory - Determine all of the existing and planned boilers, chillers, solar thermal, generators, renewables, etc. locations, sizes, age, etc.

5. Use Electric Distribution Simulation - do a grid analysis and determine the optimized distribution of the electrical system and electric renewable energy supplies.

6. Use Supply \& Distribution Optimization Simulation - use a model like "POLIS" to determine the optimal distribution and supply systems for both the thermal and electrical and the integrated loads to calculate primary energy demands with the included distribution losses.

7. Determine Centralized and De-Centralized Options - optimization needs to consider both sets of scenarios

\subsection{Financial and Emission Analysis}

Integrate energy and fuel usage using the efficient buildings and optimized distribution systems and supply scenarios calculate the fuel costs and associated emissions. Using energy, fuel, distribution and supply costs, the initial costs, investment costs, and annual income, yearly and cumulative cash flows are calculated for the project life for each scenario.

\subsection{Overall Scenario Results and Project Recommendations}

Estimate the sensitivity of important financial indicators in relation to technical and financial input assumptions and develop final results for each of the scenarios investigated. Display overall scenario results showing risk and reward for the project and make scenario/project 
recommendations with the development of the project business plan. The primary goal is to calculate the amount of energy delivered, in various forms, by the energy systems. The challenges of the model are to assess the system's energy needs in terms of heating, cooling and power generation; and then to estimate how those needs can be met by the various energy systems that are ultimately chosen. The model is devoted to calculating the system's load and energy use and to evaluating how they can be optimally met.

\subsection{Building Level Optimization}

The Army's present and future building stock is comprised of a variety of building types. Energy requirements in some of them (i.e., barracks, office buildings, child development centers, maintenance facilities and hangars) are dominated by climate (heating, cooling and humidity control) with a smaller effect from plug-in loads. Other buildings (e.g., command and control facilities, hospitals, training facilities with simulators, dining facilities, laboratories) have high energy loads dominated by internal processes and high ventilation requirements.

While some energy use reduction methods in most of these facilities are similar and well understood (building envelope improvement, better lighting systems designs and technologies, etc.), in buildings with high internal loads, energy use reduction can result only with intervention into specific processes use of energy efficient appliances and use of significant waste streams [2], which is currently rarely addressed. More work is needed to address energy uses and wastes at such energy intensive facilities like data centers, laboratories, training simulators, hospitals, etc.

The energy demand determines the amount of energy that needs to be provided by the distribution and supply generation side. Building level energy simulation and optimization can be accomplished using models such as EnergyPlus, ESPr, TRANSYS, or another accurate hourly energy analysis program. When a community or a cluster of buildings is evaluated there are more opportunities available for energy savings and more challenges for analysis and optimization. In addressing buildings as a community, you not only need to deeply evaluate each building, but you also need to take the individual analysis and apply it to a community, or cluster, with possibilities for integrated supply services.

The building optimization process starts with identifying typical buildings and energy systems on Army installations and existing energy wastes and inefficiencies related to these buildings and systems [2], developing load profiles for typical base case buildings and identifying an analysis of suites of technologies for ultra-low energy installation to include waste recovery and energy conserving (ultra-low energy), energy generation and storage technologies that could be applied to buildings and the energy systems that support those buildings to minimize traditional electrical and fossil energy use.

There is a debate over whether to conserve energy first or just generate energy with renewable alternatives. Figure below shows the theoretical path for optimization and the process for each individual building and building cluster optimization process.

Point 1 is the base case building that is either required to be built by the local code body requirements or is an existing building. If renewables are added at this point, the total annual cost of the net zero energy building will be as shown in point 8, using a constant cost for a unit of photovoltaic system ( $\$ / \mathrm{m}^{2}$ of a PV panels or $\$ / \mathrm{kWh}$ electricity produced). Another alternative from point 1 will be to add energy efficiency technologies at the building level, which will require investing in these technologies (additional first cost) and eventually point 2 is reached with the lowest total annual cost. One would not add renewables at this point since many more energy efficiency technologies can be added that are more cost effective than adding renewable generation. Point 3 is reached when the same total annual cost as existing building or base case building built to code, but this building is now much more energy efficient and in many cases much more comfortable to inhabit. By continuing to add energy efficiency improvements to the building, the building will eventually reach point 4, where adding more energy efficiency 
measures will result in diminishing returns, or cost more than adding renewable generation. For an individual building analysis, this building would be at the Net Zero Ready point. For different types of buildings and climate locations, fossil fuel based energy reduction will vary [3] for each case.

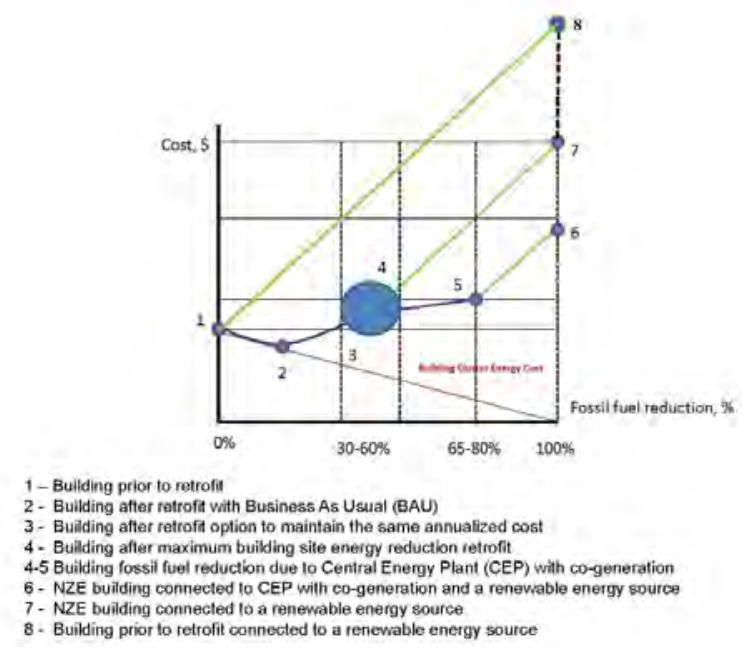

Fig. 1. Building fossil fuel reduction optimization process

In buildings with low internal energy loads, reduction of fossil fuel can be significant (50 to 75\%), but only 20 to 30\% in buildings with high internal loads. This is true even for buildings built or retrofitted to "passive house" requirements and using advanced "low exergy" systems to satisfy remaining heating and cooling needs. The remaining energy requirements will be dominated by electrical power needs for lighting, appliances and internal processes and by domestic hot water needs, i.e., for showers and other domestic needs. Adding renewables from point 4 will result in the total annual cost, shown by point 7 . Depending on the building internal load, building fossil fuel based energy reduction can reach 30 to $60 \%$.

Alternatively, the building characterized by point 4 can be connected to co-generation plant serving either this individual building or cluster of buildings. This will require a smaller investment compared to the cost of decentralized boilers and chillers for single buildings, and the cost of larger renewable generation equipment [9], but result in a significant fossil fuel reduction due to use of waste heat accompanying electricity generation. This heat can be used either to satisfy heating, cooling, and domestic hot water needs of the building cluster, or be exported to another building cluster. Connecting to a Combined Heat and Power (CHP) plant, fossil fuel usage by the building cluster (point 5) can be further reduced by another 20-25\%. When CHP uses biomass or biogas as a fuel, the connected building(s) become "Net Zero" fossil fuel. Typically at point 5 , buildings do not require additional thermal energy from renewable energy source, but may require additional electrical power. After point 5 , adding solar or wind generated electrical power becomes a cost-effective supply option, and this point, by definition, states that the building cluster is "Net Zero Ready." As one can see from the graph, path 1-2-3-4-5-6 is the lowest cost path for building improvement leading toward net-zero fossil fuel based energy strategy.

When this process has been completed for each building, the results from all of the individual buildings are integrated and put into annual load duration curves. The load duration curve shows the cumulative duration for different loads in the system over a full year. Due to diversity of energy use in buildings comprising the cluster (community), the peak of the resulting load curve is much smaller than the sum of peaks of individual buildings and thus the needed generation and a back-up capacity is much smaller. 


\subsection{Building Cluster or Installation Analysis}

To develop the community energy concept, energy models can be used that optimize distribution of energy from central generation/production to the energy usage by the buildings and systems. The building simulation gives results for demand curves for domestic hot water consumption, electricity consumption, heating, and cooling for those buildings at existing climatic conditions and these are passed to the next step. These models will minimize energy waste and losses and optimize first and operating costs (First Cost + Operating Cost $=$ Total Cost). Based on this concept, a Master Planning process can be developed that will provide an orderly approach to changing the typical Army installation to an ultra low energy consuming community.

\subsection{Distribution and Supply Optimization}

Simulation of supply systems can be done using an energy system optimization model like POLIS [4]. Between energy generation and energy demand points (at each building level), a distribution system is used to transport the energy via a hot or chilled water system. While "energy balancing" means just calculating the correct energy flows (and perhaps also carbon emissions) in a system, to estimate energy costs and to benchmark with other similar systems, simulation and optimization is necessary for system planning. For principal comparisons of available alternatives, a simpler simulation approach will be favorable, one that provides a possibility to make an energy balance for the whole system and to compare the effects of different demand or supply side measures in terms of energy efficiency, capital and energy costs, and GHG (Green House Gas) emissions with the simulated demand curves from the building simulation optimization step.

For this purpose, energy system models might be applied that have been developed for the optimization of large systems. However, to be used as a regular planning tool, skilled planners are needed that are familiar with them. POLIS models an energy system as a closed system including the entire chain from demand, the distribution system, to supply systems. Every element like buildings, boilers, generators, grids, etc. are described as "knots"; energy- and cost-related parameters are linked together to an interconnected system in which different usages are interlinked. Power supply, heating, and air-conditioning is modeled in a common system. This offers the opportunity to compare efficient technologies like co-generation (power + heat) and trigeneration (power + heat + cooling). The result of this type of model offer the best suited solution to reduce the energy usage of a building cluster, and leads the way to net zero installations with least cost. More than that, the approach of optimizing building clusters will offer new and/or additional options that reduce the fossil energy footprint of community systems cost efficiently.

In POLIS, an energy system can be modeled by using prototypes of generation equipment, distribution systems, and load profiles. Cost, emissions, and technical parameters are used to describe existing or future elements of the system. Simulation is performed using hourly load profiles for the thermal and electrical energy demand throughout a year (8760 hours), which is generated from the summation of the building cluster energy simulations. POLIS allows calculation of the best suited combination of paths to meet the load with the objective to minimize total system costs, or minimize total GHG-emissions. Since the distribution systems play a significant role in an overall thermal energy system, a hydraulic flow model should be used to analyze critical capacities and flows in the system. Through an iterative process, these two models will determine whether an optimization of the energy system (POLIS results) will lead to a feasible optimized supply and generation system.

\section{Fort Irwin, CA Building Cluster Case Study Results}

The integrated energy optimization process described to this point includes analysis of building energy efficiency improvements and optimization of energy generation and distribution. The tools required to optimize an individual building were applied to the analysis of eight types of Army buildings. The goal was to meet or exceed EPACT 2005 requirements for new construction $[5,6,7]$ as well as for the "Integration of Energy/Sustainable Practices into Standard Army 
MILCON Designs” study [3] of five common types of Army buildings with aggressive goals to achieve 60 to $80 \%$ energy use reduction against CBECS 2003. Continuing the discussion started in [8], this section of the paper illustrates the proposed approach using the example of the building cluster to be renovated at Fort Irwin.

Fort Irwin is located in the High Mojave Desert midway between Las Vegas, NV and Los Angeles, CA. The energy required to serve the needs of more than 1600 buildings located on the installation is not generated on site; it must be conveyed over long distances. Electric power is transmitted from distant generators through the power grid; LPG for heating and domestic hot water (DHW) is trucked to Fort Irwin in bulk.

The Engineer Research and Development Center, Construction Engineering Research Laboratory (ERDC-CERL), with support from a group of industry experts, conducted an energy study [9] at Fort Irwin with a focus on a representative group (cluster) of buildings that included five barracks buildings, a dining facility, and a central energy plan to which all these buildings were connected. The integrated optimization process used in this analysis includes optimization of each building in the cluster to meet its economic energy efficient optimum. The building cluster is then energy optimized taking advantage of the diversification between energy intensities, scheduling, and waste energy streams use between the buildings.

\subsection{Modeling of Buildings and Systems}

The modeling of the buildings, the systems within the buildings, and the systems supporting the buildings was done by using the eQuest - an hourly annual building energy analysis tool that provides professional-level results with an affordable level of effort.

The estimated energy use of the five barracks and dining facility as operating during the site visit was $3.1 \mathrm{million} \mathrm{kWh} / \mathrm{yr}$ and 9193 million Btu (2,694,202 kW-hr) of LPG gas. The data generated by computer analysis indicate that a typical upgrade of a barracks building only saves $8 \%$ of the electricity use compared to the barracks "as we found them" and $7 \%$ of the heating energy. In other words, a typical barracks upgrade is not very energy efficient.

The results of further analysis (Table 1) show that upgrades to Net Zero energy ready buildings allow the reduction of the energy consumed to heat, cool, and ventilate the cluster facilities by 44 to $49 \%$ of electrical use and 30 to $59 \%$ of heating use with paybacks of 2 to 10 yrs depending on the alternative chosen. Since the proposed energy efficiency work includes the implementation of DOAS and high efficiency dehumidification systems that would dramatically reduce the potential for biological growth, in climates where mold is an issue, the avoided costs of mold mitigation can decrease the payback to 1.2 yrs.

A renewable energy use analysis to achieve "Net- Zero" energy status building cluster must provide the remaining energy amount using renewable energy sources. For the location of Fort Irwin, the most attractive renewable energy sources are solar and waste products. For development of the renewable energy concepts the following exiting conditions were used. The Barracks and the Dining Facility are connected to the Central Heating Plant (Bldg 263) by a district heating grid. Three LPG boilers, $2060 \mathrm{MBtu} / \mathrm{hr}(603 \mathrm{~kW})$ each, are generating heat for domestic hot water DHW needs and space heating (SPH). No water storage tanks are installed in the Central Heating Plant. DHW storage tanks with a capacity of approximately 1500 gal (5678 L) are installed in each building. The LPG and electricity prices are the actual values given during the energy assessment. Renewable energy opportunities for the building cluster, including installing solar thermal, biomass (wood chip), and PV electrical generation systems can save 4832 million Btu/yr (1,416,119 kW-hr/yr) and generate 41,630 KWh/yr. Renewable thermal energy generation is cost effective and has a simple payback period of less than 10 years. Using photovoltaic panels to generate renewable electrical energy is not a cost effective solution since it has a significant payback period of 47 years. 


\section{Conclusions}

The integrated optimization process is being developed under the Army research and development project "Modeling Net Zero Installations-Energy (NZI-E)" [11] and the International Energy Agency (IEA) Energy Conservation in Buildings and Community Systems (ECBCS) Annex 51. The process includes optimization of each building clustered together to meet its economic energy efficient option; then the building cluster is also energy optimized taking advantages of the diversification between energy intensities, scheduling, and waste energy streams use. The optimized cluster connected to CHP plant will minimize the amount of renewables needed to make the building cluster Net Zero fossil fuel energy.

The recommended, integrated energy solution demonstrates that vastly improved energy efficiency and greenhouse gas reductions are feasible in the context of a normal scale development using proven approaches from the United States and elsewhere.

"Business as usual” leads to individual boilers and chillers for each building, which leads to significant total overcapacity, and over time, to a wide range of boiler inefficiencies and chiller COP's with limited overall system control to meet the diverse demands of an installation. Alternatively, district heating and cooling systems link buildings in common networks that eliminate inefficient boiler and chiller over-capacity, and allow the integrated system to meet the integrated peak loads instead of individual peak loads. The addition of efficient technologies now, allows future technologies to be added to one location instead of to each building at the location.

\section{References}

[1] Army vision for Net Zero. Net Zero is a force multiplier, Washington, DC: Office of the Assistant Secretary of the Army (Installations, Energy \& Environment), 15 December 2010, www.asaie.Army.mil

[2] Energy and Process Assessment Protocol, International Energy Agency (IEA) Energy Conservation in Buildings and Community Systems (ECBCS) Annex 46, http://www.annex46.org/

[3] USACE Report on EISA Study, Army MILCON Energy Enhancement and Sustainability Study of Five Buildings, (A collaboration by USACE, ERDC-CERL, NREL, PNNL).

[4] Richter, S., and T. Hamacher. "URBS: A Model for Investigations on Future Urban Energy Systems.” PowerGen Europe, Conference Proceedings. International Conference and Fair. CCD Düsseldorf, Germany, May 2003.

[5] Zhivov, A., D. Herron, and M. Deru. "Achieving Energy Efficiency and Improving Indoor Air Quality in Army Maintenance Facilities.” ASHRAE Transactions. LO-09-094, 2009, Vol 115, Pt 2.

[6] Herron, D., A. Zhivov, and M. Deru. "Energy Design Guides for Army Barracks,” ASHRAE Transactions, 2009, LO-09-093, Vol 115, Pt 2.

[7] Deru, M., D. Herron, A. Zhivov, D. Fisher, and V. Smith, "Energy Design Guidelines for Army Dining Facilities,” ASHRAE Transactions, LO-09-095, 2009, Vol 115 , Pt 2.

[8] Zhivov, A, R. Liesen, S. Richter, R. Jank and F. Holcomb, "Towards a Net Zero Building Cluster Energy Systems Analysis for a Brigade Combat Team Complex.” Proceedings of ASME 2010 4th International Conference on Energy Sustainability, ES2010-90487, 17-22 May 2010. Phoenix, AZ, USA.

[9] David M. Underwood, Alexander Zhivov, Scot Duncan, Alfred Woody, Curt Björk, Stephan Richter, Dieter Neth, Dan Pinault, and Reinhard Jank. Working Towards Net Zero Energy at Fort Irwin, CA. ERDC/CERL TR-10-24. Champaign, IL: ERDC-CERL, 2010, http://www.cecer.Army.mil/techreports/ERDC-CERL TR-10-24/ERDC-CERL TR-1024.pdf 